\title{
Early Nuclear Events after Herpesviral Infection
}

\author{
Florian Full *(i) and Armin Ensser *(i) \\ Institute for Clinical and Molecular Virology, University Hospital Erlangen, Friedrich Alexander University \\ Erlangen-Nuremberg, 91054 Erlangen, Germany \\ * Correspondence: Florian.Full@uk-erlangen.de (F.F.); armin.ensser@fau.de (A.E.)
}

Received: 23 July 2019; Accepted: 3 September 2019; Published: 7 September 2019

\begin{abstract}
Herpesviruses are important pathogens that can cause significant morbidity and mortality in the human population. Herpesviruses have a double-stranded DNA genome, and viral genome replication takes place inside the nucleus. Upon entering the nucleus, herpesviruses have to overcome the obstacle of cellular proteins in order to enable viral gene expression and genome replication. In this review, we want to highlight cellular proteins that sense incoming viral genomes of the DNA-damage repair (DDR) pathway and of PML-nuclear bodies (PML-NBs) that all can act as antiviral restriction factors within the first hours after the viral genome is released into the nucleus. We show the function and significance of both nuclear DNA sensors, the DDR and PML-NBs, and demonstrate for three human herpesviruses of the alpha-, beta- and gamma-subfamilies, HSV-1, HCMV and KSHV respectively, how viral tegument proteins antagonize these pathways.
\end{abstract}

Keywords: Herpesviruses; double-stranded DNA virus; DNA-damage repair; DNA-damage response; nuclear DNA sensors; restriction factors; HSV-1; Herpes simplex virus; CMV; cytomegalovirus; KSHV; Kaposi's sarcoma-associated herpesvirus; double strand break; NHEJ; non-homologous end joining; HR; homology repair; infection; virus; PML; PML nuclear bodies; ND10; virus-host interaction; SP100; DAXX; ATRX; ICP-0; IE-1; ORF75; HHV-6

\section{Introduction}

Herpesviruses have evolved sophisticated ways to subvert the immune system over millions of years of coevolution with their respective hosts. While herpesviruses also need to surmount adaptive cell-mediated immunity in order to prevent being killed by immune cells and establish persistent infection, the antagonism of cellular restriction and the innate immune system is of particular importance in order to achieve efficient infection of target cells. The nine human members of the herpesvirus family include important human pathogens, i.e., Herpes-simplex viruses-1 and -2 (HSV-1 and HSV-2), the Varicella-Zoster Virus (VZV), Human Cytomegalovirus (HCMV), Human Herpesviruses-6A, -6B and -7, and the tumor viruses Epstein-Barr virus (EBV) and Kaposi's sarcoma associated herpesvirus (KSHV) [1]. A hallmark of herpesvirus infections is the establishment of lifelong latency [1]; for example, about 3.7 billion people are infected with HSV-1 worldwide [2], and even more by HHV-6, -7, and EBV [3,4]. In this regard, herpesviruses are the most "successful" virus family in the human population, because almost all human adults are latently infected with at least one herpesvirus, and most by several. Herpesviruses are double-stranded DNA viruses with genome sizes from 125-250 kbp [1]. For the infection of target cells, herpesviral virus particles bind to cellular surface receptors. Virus particles are internalized, by fusion or endocytosis, the capsids are transported to the nucleus, and the linear genome is released into the nucleus through nuclear pores. Whereas the viral genome is enclosed and protected by capsid proteins in the cytoplasm, upon injection into the nucleus, the naked linear viral DNA is especially vulnerable to detection by cellular DNA-damage proteins and to attack by cellular restriction factors. Therefore, the viruses had to evolve ways to (i) prevent 
detection of the genome by DNA-damage proteins; (ii) prevent degradation of the naked, linear viral DNA; (iii) realize recircularization of the viral genome; (iv) achieve chromatinization of the genome, but simultaneously, prevent the addition of repressive chromatin marks, and (v) establish efficient viral gene expression. In our review, we want to focus on the nuclear events of herpesviral infection in the first hours after the viral genome enters the nucleus by focusing on one human member of each of the alpha-, beta-, and gamma-herpesviruses, namely HSV-1, HCMV, and KSHV. We try to highlight the critical steps and their importance for the herpesviral life cycle, and show similarities and differences between herpesvirus subfamilies. In addition, we want to demonstrate how herpesviral proteins, in particular tegument proteins that enter the cell as part of the viral particle, antagonize cellular restriction factors.

\section{DNA Sensor Proteins}

Upon infection, the viral capsid is transported through the cytoplasm along the cytoskeleton until it reaches the nuclear membrane; there, the viral genome, which is coiled in the capsid under high pressure, is injected through nuclear pores [5]. In the cytoplasm, sensing of viral DNA by DNA-sensors like AIM2 and cGAS leads to the activation of both the STING-IRF3-NF-kB pathway and the inflammasome; this results in antiviral cytokine production, including interferon and interferon-stimulated genes [6-8]. AIM2, cGAS, and STING are predominantly located in the cytoplasm, which has prompted controversy about the mechanisms of herpesviral DNA-sensing [9]. Given the model of infection described above, capsid proteins always protect the viral DNA, and there is no naked viral DNA present in the cytoplasm during the natural way of infection $[5,10]$. However, at least after replication in cell culture, the majority of herpesviral particles are not able to establish infection, as reflected by (packaged genome copies: plaque forming unit) ratios of $>10-1000$. In addition, there are also many empty capsids and virions present. Thus, it is conceivable that there is sensing of such defective viral particles that may contain or spill accessible and unprotected viral DNA. The uptake of such defective particles by cells during infection may initiate cGAS- and STING-dependent signaling events that elicit a potent type-I IFN response. In addition, the cellular protein IFI16 has also been shown to act as a sensor for herpesviral DNA [11-13]. Most work on IFI16 as an antiviral sensor was done with HSV-1, and the data about the antiviral role was partially controversial, in particular with respect to the effect of the depletion of IFI16 on herpesviral replication and the role of ICP0 in the degradation of IFI16 [14]. Nevertheless, it is well accepted that IFI16 has an important function in sensing herpesviral DNA [9]. In contrast to cGAS and STING, IFI16 is a predominantly nuclear protein [11,12], and most publications point at nuclear sensing of herpesviral DNA by IFI16 [14]. In the initial publication describing the antiviral role of IFI16, it was proposed that IFI16 could shuttle between the nucleus and the cytoplasm to initiate innate immune signaling [15]. IFI16 can be acetylated within its nuclear localization signal, which results in the translocation of the protein to the cytoplasm [13]; for KSHV, this acetylation, followed by translocation, might be involved in sensing the virus [16]. However, it was also shown that a fraction of cGAS can locate to the nucleus in primary cells, and that cGAS stabilizes IFI16, and thereby promotes, the sensing of HSV-1 [17]. Moreover, several reports suggest that IFI16 could be directly associated with herpesviral DNA in the nucleus $[16,18]$, most likely mediated through oligomerization via its Pyrin domains [19]. As a consequence of oligomerization, IFI16 can form filamentous structures in viral replication compartments after infection with an ICP0-deficient HSV-1, and it is thought that these structures restrict viral gene expression [20]. For HCMV, the knockdown of IFI16 has been shown to facilitate viral replication [21], and HCMV also encodes for a protein, pUL83 (pp65), that prevents oligomerization of IFI16 via its Pyrin domains, and thereby inhibits innate immune activation [22]. A recombinant HCMV with a deletion of the pp65 gene showed an increase in IFN-beta production compared to wildtype HCMV, which illustrates the importance of IFI16 in the innate immune response to herpesviral infection. In contrast to HCMV, HSV-1 infection results in the degradation of IFI16. It is unclear whether this degradation is mediated by ICP0 [14]. While some publications show that the degradation of IFI16 is mediated by ICP0 [12], others show that this degradation is independent of 
ICP0 [23], and that ICP0 even prevents the association of IFI16 with viral DNA [23,24]. Most likely, the observed differences can be explained by cell type-specific regulation of IFI16 in response to HSV-1 infection [25]. Similar to HSV-1, degradation of IFI16 has also been shown during the lytic reactivation of KSHV [26] as an immune evasion mechanism to prevent inflammasome activation [27]. KSHV infection leads to inflammasome activation through a unique mechanism that includes IFI16 and BRCA1 translocation into the cytoplasm [28]. In addition to BRCA1, IFI16 also recruits histone $\mathrm{H} 2 \mathrm{~B}$ and the acetyl-transferase p300 to sites of viral genomes [29]. Subsequently, H2B and IFI16 get acetylated by $\mathrm{p} 300$, which leads to translocation of the entire IFI16-BRCA1-p300-H2B complex into the cytoplasm, followed by inflammasome activation and Il1-beta secretion [29]. Mechanistically, the direct restriction of gene expression by IFI16 could be explained by the introduction of repressive histone modifications on viral chromatin, as has been reported for HSV-1 [11,30]. More studies are needed to identify the cellular enzymes that mediate respective histone modifications and whether they are directly recruited by IFI16 to viral genomes. IFI16 is rapidly recruited to incoming viral genomes $[18,22]$, and several studies show IFI16 oligomerization in the proximity of viral genomes at later time points using confocal and live cell microscopy $[19,31]$. Intriguingly, there was no evidence for the association of viral DNA with IFI16 or PML-NBs after nuclear entry of adenoviruses [32,33]. It could be that there is a fundamental difference in the recognition of herpesviruses and adenoviruses by IFI16. In addition, the detection of incoming viral genomes is technically challenging, which makes it difficult to perform in-depth biochemical analyses. Nevertheless, it was demonstrated by confocal microscopy in a recent study by the Knipe lab that IFI16 and ATRX independently localize to EdC-labelled HSV-1 genomes as early as $15 \mathrm{~min}$ and until $60 \mathrm{~min}$ post infection, but viral heterochromatin formation was independent of IFI16 [34]. For a more detailed assessment of all cellular DNA-sensing and immune-evasion of herpesviral infection, however, we would like to recommend the excellent reviews by Stempel and colleagues and Orzalli and colleagues, both of which discuss the current knowledge in great detail $[35,36]$.

\section{DNA Damage Response Proteins}

The relationship between herpesviruses and cellular DNA-damage response (DDR) proteins is controversial [37]. While selected DDR proteins are beneficial for viral replication, and are even actively recruited into viral replication compartments at later stages of the lytic cycle, the virus has to antagonize at least parts of the DDR at early stages of infection. Although there are only few reports of early herpesviral antagonism of the DNA damage response, the well-studied DNA viruses from the adenovirus family can serve as an archetypical example. In this regard, adenoviruses have been shown to inhibit several components of the DDR after infection, in particular the non-homologous end-joining (NHEJ) pathway, in order to promote viral replication [38-40].

Cellular DDR is composed in a modular way [37]. On top of the cascade are proteins that sense DNA damage event by directly binding to damaged DNA, hallmarked by DNA double strand breaks or single-stranded DNA. The Ku70/Ku80 heterodimer, as well as the Mre11/RAD50/NBS1 (MRN) complex, recognize DNA double strand breaks [41]. In addition, the RPA protein binds to unusual stretches of ssDNA at stalled or stressed replication forks, recruiting ATRIP. After DNA binding, a carboxyterminal motif of one of each sensors (NBS1, ATRIP, KU80 respectively) interacts with its corresponding member of the large phosphatidylinositol-3-kinase like kinases (PI3KKs), ataxia telangiectasia mutated (ATM), ataxia telangiectasia mutated (ATR), and the DNA-dependent protein kinase catalytic subunit (DNA-PKcs), and induces their autophosphorylation and activation [41]. DNA double strand break sensing by the MRN complex leads to the activation of ATM, whereas ssDNA sensing by RPA activates ATR. The activated PI3KKs then phosphorylate the downstream protein $\mathrm{H} 2 \mathrm{AX}$ at serine residue 139 (the phosphorylated form is called $\gamma \mathrm{H} 2 \mathrm{AX}$ ). $\mathrm{H} 2 \mathrm{AX}$ is a DNA damage-specific histone variant, and its phosphorylation results in the recruitment of additional factors to the site of DNA damage like RNF8 and RNF168. 
The initiation of the DDR cascade is a fast process. All proteins are ubiquitously present in the nucleus, and upon activation, the phosphorylation cascade leads to locally-restricted DDR activation at the point of damage [41]. In addition, there is co-regulation with the cell cycle. From a cellular point of view, the DNA damage must be detected and resolved before the progression of the cell cycle to prevent further mutations and passing of the DNA damage to daughter cells. Therefore, a DDR also results in the activation of cell cycle checkpoints to prevent the replication of damaged DNA. ATM, as well as ATR, phosphorylate checkpoint kinases CHK1 and CHK2, which results in a G1-S-phase checkpoint arrest by activating the tumor suppressor p53.

The herpesviral genome enters the nucleus in its naked and linear form [5]. The viral genome ends resemble DNA double strand breaks (DSB), and in normal cells, a chromosomal DSB is a severe DNA-damage event that is sensed by DDR sensors and repaired immediately. Moreover, it has been demonstrated for HSV-1 that the incoming viral genome contains nicks and gaps that could also activate cellular DDR signaling [42]. Cellular chromosomes are also linear DNA molecules, but their ends are protected by telomeres [43]. Most herpesviral genomes, however, don't have terminal telomeric repeats or similar structures, and therefore, the viruses have to prevent the initiation of a cellular damage response in order to avoid unwanted repair of their genomes early after infection. Of course, there are exceptions: the genomes of human Herpesviruses-6 (HHV6-A and HHV-6B) and -7 contain human telomere-like sequences [44]. Interestingly, while almost all other herpesviral genomes persist as episomal DNA molecules in infected cells after the establishment of latency, germline-integrated HHV-6 genomes have been reported in approximately $1 \%$ of patients. In these, the viral genome is found in telomeric regions, to which it is targeted via its viral telomere sequences $[45,46]$. As these viruses seem not to yield infectious progeny, the significance of this host genome integration for viral pathogenesis is currently under investigation [44].

It could be demonstrated for all herpesvirus families that specific DDR proteins are activated at later stages of the herpesviral replication cycle during lytic replication. Once viral replication compartments are formed, several DDR proteins are recruited into replication compartments. It has been shown for HSV-1 that ATR and ATRIP are recruited to viral replication compartments, and that ATR pathway proteins are needed for efficient viral replication [47-49] while downstream ATR signaling is blocked simultaneously [48,50-52]. Excellent work by the Weitzman lab showed that ATM and MRE11 are also activated and needed for efficient viral replication [53,54]. In addition, several cellular DDR proteins, including members of the mismatch repair complex (MSH2, MSH6), the double strand repair protein RAD50, and members of the single-strand repair complex (XRCC1, PARP1), among others, have been demonstrated to associate with viral DNA replication forks by the precipitation of EdC-labeled viral DNA [55], indicating a role of selected DDR proteins during HSV-1 replication. In the case of KSHV, both the Ku70/80 complex, as well as MRN complex, colocalize with viral replication compartments [56] and lytic replication of KSHV activates ATM, DNA-PK, and $\gamma \mathrm{H} 2 \mathrm{AX}$, but not ATR and CHK1 signaling [57]. As mentioned above, DDR proteins are equally distributed in the nucleus, and it has been demonstrated for HCMV that a great number of DDR proteins are activated upon infection, but only a fraction colocalize with viral DNA [58], pointing at a selective regulation of access to viral replication compartments. Therefore, it is important to assess the subnuclear localization of DDR proteins relative to viral DNA to discriminate unspecific global bystander activation and specific local responses. For HCMV, it was further demonstrated that infection results in ATM activation and downstream signaling, leading to the activation of p53 and $\gamma \mathrm{H} 2 \mathrm{AX}$, and that this is required for efficient viral replication [59-63]. Taken together, all members of the alpha-, beta- and gamma-herpesvirus subfamilies have in common that they activate the ATM response at later time points during infection, indicating an important role of ATM activation for viral replication. Furthermore, an additional, unique set of DDR proteins are activated for each individual virus.

However, we hypothesize that the viruses need to block the cellular DDR immediately after infection to prevent the repair of incoming linear genomes. (Figure 1) Herpesviral infection usually takes place in quiescent cells [64]. During the G1- and G0-phase, the NHEJ pathway, activated by 
KU70/KU80, is the default repair pathway for DSBs. In contrast, the homologous repair (HR) pathway, which is activated by the MRN-complex via ATM, is active during S-phase and G2-phase when sister chromatids are present as a template for homologous recombination. Repair through NHEJ would lead to a loss of genetic information for the virus due to DNA end processing prior to ligation by DNA ligase IV/XRCC4. As mentioned, adenoviruses, a dsDNA virus family that also replicates in the nucleus, have evolved potent mechanisms to block NHEJ. Therefore, we think that herpesviruses also need to block NHEJ in favor of HR in order to achieve the loss of recircularization of their genomes. It was demonstrated that the NHEJ protein PAXX acts as a restriction factor for HSV-1 replication [65]. PAXX interacts with Ku80 and gets relocated after HSV-1 infection, and depletion of PAXX has been shown to enhance HSV-1 replication [65]. For KSHV, the depletion of Ku80 and DNA-PK, two proteins involved in NHEJ, leads to enhanced genome replication [56]. Another important protein in this regard is SPOC1, a cellular chromatin remodeling factor that inhibits immediate early gene expression of HCMV and also adenoviruses [66,67]. Upon DNA damage, SPOC1 is recruited to DNA double strand breaks by ATM signaling, promotes HR-repair, and blocks NHEJ. Moreover, SPOC1 interacts with KAP-1, inhibits KAP-1 phosphorylation, and enhances H3K9 trimethylation [68]. Although SPOC1 showed the unambiguous features of an antiviral restriction factor, surprisingly, it was found to be actively upregulated by the HCMV protein IE-1 shortly after infection [66]. Since SPOC1 restricts both adenoviruses and HCMV, it would be very interesting to see whether SPOC1 also restricts the herpesviruses of the alpha- and gamma-subfamilies.

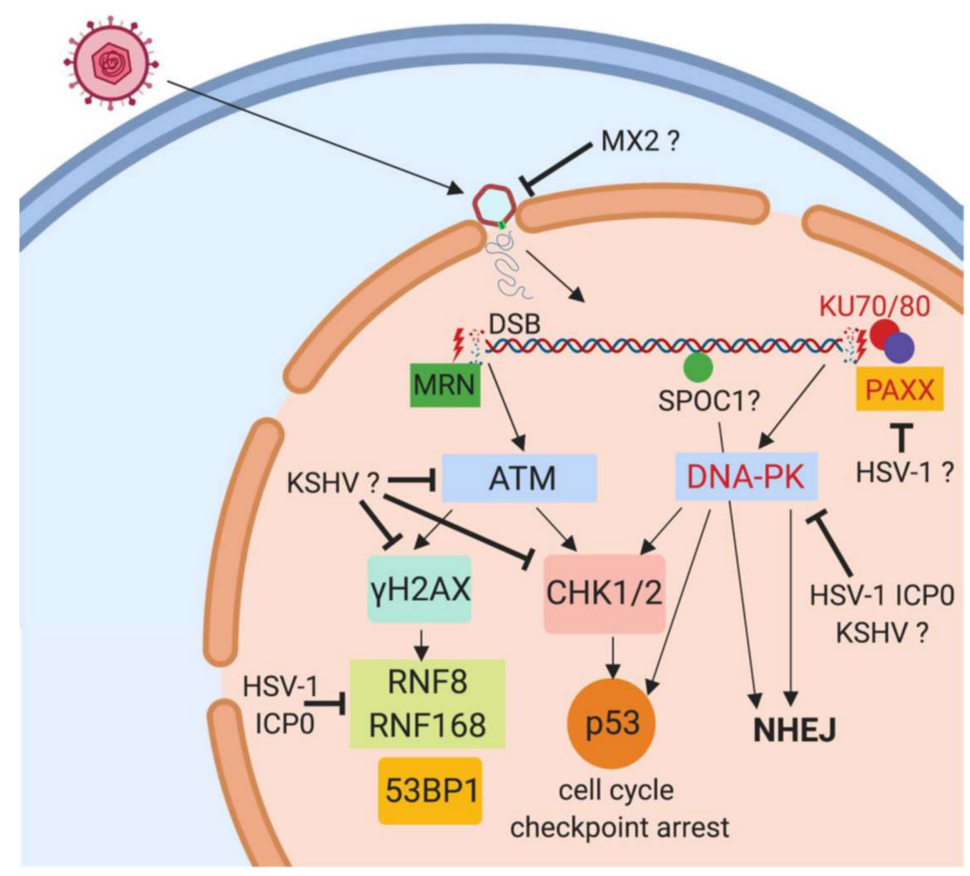

Figure 1. Herpesviral antagonism of the ATM- and DNA-PK-branch of the DDR directly after infection. After infection of target cells, the herpesviral capsid is transported to the nuclear membrane and the viral DNA released into the nucleus through nuclear pores. We propose that the cellular DDR complexes recognize the viral linear DNA by MRN- and KU70/KU80-complex binding to double-strand break resembling ends of the linear viral DNA. This results in activation of kinases ATM and DNA-PK respectively, followed by phosphorylation of $\mathrm{H} 2 \mathrm{AX}(\gamma \mathrm{H} 2 \mathrm{AX})$ and $\mathrm{CHK} 1 / 2$ and activation of downstream proteins including the cell cycle regulator p53. HSV-1, HCMV and KSHV have been shown to counteract this activation as indicated in the graph, however, the viral effector proteins and mechanisms are not identified. Depletion of proteins depicted in red font has been shown to enhance herpesviral replication, indicating an inhibiting role on herpesviral replication. ? indicates an unknown mechanism. 
In general, it is challenging to assess the early events minutes after viral infection, considering that under physiological conditions, only one or very few viral genomes enter the nucleus upon infection, and that one must discriminate between viral and cellular DNA. On these grounds, it is conceivable that data on these early events are partially conflicting. For example, it is textbook knowledge that the incoming linear viral genomes have to undergo recircularization before viral genome replication begins. However, controversial data has been published on whether or not HSV-1 genomes undergo recircularization upon infection $[69,70]$. In addition, it was assumed that herpesviral genomes were amplified by rolling circle replication during lytic infection of HSV-1, and that HSV-1 proteins were indeed able to induce rolling circle replication in vitro [71,72]. In contrast, HSV-1 replication also leads to replication intermediates that hint at an alternative recombination-based mechanism of replication [73-76]. Nevertheless, it is beyond doubt that independent of the mode of genome recircularization and viral DNA replication, a loss of genetic information would be detrimental for viral replication. Therefore, it is advantageous for a herpesvirus to prevent NHEJ, and instead, to create an environment that promotes homologous recombination. The ends of linear herpesviral genomes contain at least two but up to 50 repeats (depending on the herpesvirus) that are homologous to each other. These repeats can serve as templates for homologous recombination, and enable genome circularization. From the concatemers formed by rolling circle replication, linear genomes with flanking repeats can reform without losing genetic information, similar to sister chromatids during S-phase. Newer and more sensitive imaging-based detection methods like EdC-/EdU-labeling of viral genomes and fluorescent in situ hybridization-based techniques with single molecule sensitivity could help to resolve these controversies in the future. For example, very elegant work by Jill Dembowski and Neal DeLuca using EdU-labeled viral genomes followed by click-chemistry demonstrated an association of several DDR proteins including 53BP1, PARP1, PARP14, MRE11A, and Ku70(XRCC6) with HSV-1 DNA at early time points post infection [77]. However, one has to consider that EdC/EdU-labeled genomes can be sensed by cellular DNA-damage sensors and induce DDR signaling, which might make an assessment of the results difficult [78,79].

HSV-1 genomes alone are able to induce DNA-PK activation [42]; however, this activation is abrogated upon viral infection by proteasomal degradation of the catalytic subunit of DNA-PK by ICP-0 [80,81]. In addition, HSV-1 replication is drastically enhanced in Ku-deficient cells [82], indicating an inhibitory role of the NHEJ pathway in HSV-1 replication. For HSV-1, it was further demonstrated that both RNF8 and RNF168 are antiviral proteins that are counteracted by HSV-1 protein ICP- 0 [83,84]. The viral ubiquitin E3 ligase ICP-0 mediates the proteasomal degradation of RNF8 and RNF168, and thereby, prevents recruitment of downstream proteins like BRCA1 and 53BP1 to $\gamma \mathrm{H} 2 \mathrm{AX}$ foci $[83,84]$. RNF8 and RNF168 have also been shown to mediate ubiquitination of histone H2A, and thereby, induce genome silencing [85].

Taken together, we think that blocking NHEJ immediately after infection and creating a nuclear environment favoring homologous recombination is beneficial for herpesviruses by promoting genome replication and preventing loss of viral genetic information.

\section{PML Nuclear Bodies}

After entering the nucleus, herpesviral genomes have been shown to associate with subnuclear structures called PML-nuclear bodies (PML-NBs, or Nuclear Domain 10 (ND10)) [86]. (Figure 2) PML-NBs are named after their key structural component, the promyelocytic leukemia protein (PML or TRIM19). PML is a TRIM protein containing the eponymous tri-partite motif that confers E3-ligase activity. PML is a SUMO-E3 ligase, and accordingly, PML-NBs are described as principal aggregations for SUMOylated proteins in the nucleus. PML-NBs are also involved in other important nuclear functions as storage organelle for nuclear proteins and centers for active transcription. For a detailed overview on the architecture and the multiple functions of PML-NBs, we recommend excellent reviews by others [87]. However, most importantly, PML-NBs are nuclear sites that mediate the antiviral restriction of DNA-virus gene expression and replication [88,89]. Several PML-NB components like 
PML itself, SP100, DAXX, and ATRX are bona fide restriction factors for viral infection, undermined by the observation that PML-NB components like PML, Sp100, and DAXX are induced by interferon [90]. DAXX and ATRX form a histone chaperone complex that recruits the non-canonical histone variant $\mathrm{H} 3.3$ to incoming viral genomes, as has been reported for the adenoviruses, HCMV and EBV [91-93]. In the case of HSV-1, H3.3 is also recruited by the histone chaperone HIRA [94,95]. Moreover, DAXX and ATRX interact with epigenetic modifiers like HP1 and histone methyl-transferase EZH2. It is thought that thereby a repressive chromatin environment is generated that mediates the epigenetic silencing of incoming viral genomes, and thus hampers viral gene expression and replication. For HSV-1, it was demonstrated that viral chromatin is established on the incoming genome as early as $1-2 \mathrm{~h}$ post infection [96]. Interestingly, predominantly repressive histone modifications like H3-lysine 9-tri-methylation (H3K9me3) and H3-lysine 27 trimethylation (H3K27me3) can be found on viral chromatin, which prevents viral gene expression and replication [96]. As mentioned above, ATRX, PML, and IFI16 are associated with the HSV-1 genome within the first hour after infection, and initial heterochromatin formation is dependent on ATRX [34]. For HCMV, viral genomes become associated with PML after infection, and similar to HSV-1, expression from the major immediate-early promoter (MIEP) is also repressed through histone modification of the region [97-99].

PML is the key protein of PML-NBs that forms a lattice and serves as a docking site for other PML-NB components, and the degradation of PML leads to a dispersal of all PML-NB proteins. Studies by Gerd Maul and colleagues have suggested that PML-NBs are needed for efficient viral gene expression [100]; meanwhile, it is well accepted in the field that PML-NBs reflect an antiviral entity in the nucleus, which is also supported by several hundred publications encompassing almost all DNA viruses $[87,90]$.

The viruses in turn have evolved mechanisms to antagonize restriction by PML-NB. (Figure 2) In this review, we focus on the early events after infection, and thus, on the tegument proteins of HSV-1, HCMV, and KSHV; for herpesviral proteins that are de novo expressed at immediate, early, and later time points, and that antagonize PML-NBs, we recommend reviews by others $[89,101]$. In the case of HSV-1, the proteins VP16 and ICP0 facilitate viral gene expression and the removal of viral heterochromatin [102,103]. ICP0 was one of first viral proteins discovered to antagonize PML [104]. ICP-0 is an immediate early protein of HSV-1, and also part of the virus particle. It is a ubiquitin E3 ligase that mediates the ubiquitin-mediated degradation of target proteins, including PML [105]. An HSV-1 ICP-0 deficient virus, as well as HCMV, was restricted by PML, DAXX, and Sp100 in a cooperative manner, shown by shRNA depletion of individual proteins [106]. The replication of the ICP-0 deficient virus was affected at different replication steps [107], further corroborating the importance of PML-NB proteins on viral replication and also the role of ICP-0 in antagonizing PML-NBs. As mentioned, PML-NBs are linked to SUMOylation, and interaction between PML-NB components heavily depends on interaction between SUMOylated proteins and SUMO-interaction motif (SIM-) containing proteins [87]. Accordingly, herpesviruses have also evolved ways to target the SUMOylation of proteins in general to antagonize PML-NB function. Excellent work by the Everett lab demonstrated that ICP-0 acts as a SUMO-targeted ubiquitin ligase (STUbL) which recognizes SUMOylated proteins and ubiquitinates them [108]. K48-linked ubiquitination of SUMOylated proteins by ICP-0 leads to the subsequent proteasomal degradation of target proteins [108].

In the case of HCMV, two proteins have been shown to be of particular importance for PML-NB antagonism: the tegument protein pp71 and the immediate-early protein 1 (IE-1). pp71 enters the nucleus together with the viral genome and induces the degradation of DAXX and the sequestration of ATRX from PML-NBs [109,110]. This first line of PML-NB antagonism enables the expression of immediate-early proteins including IE-1. IE-1 in turn efficiently dissolves PML-NBs [111], in particular by interfering with the de novo SUMOylation of PML [112], and thereby enables the expression of early genes. Most protein-protein interactions in PML-NBs are mediated by SUMOylation; therefore, SUMOylation of PML is essential for the formation of PML-NBs [87]. 


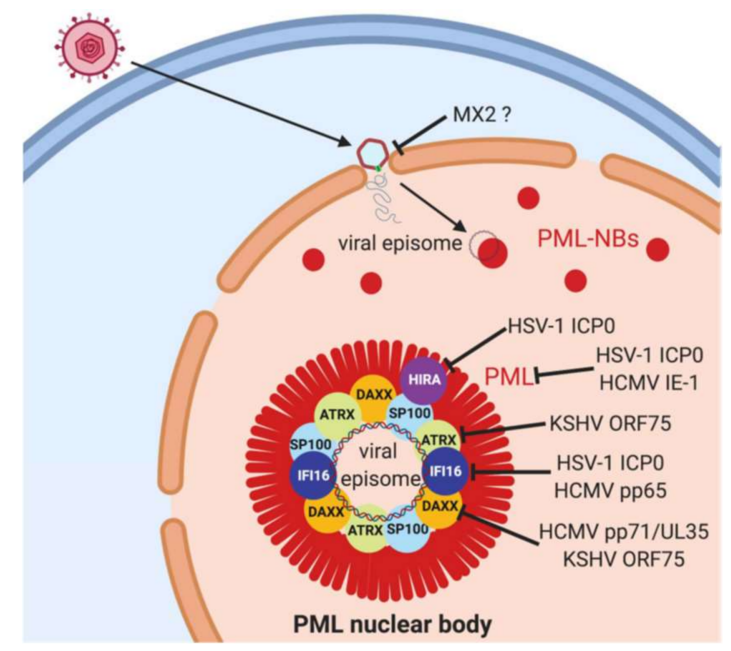

Figure 2. Herpesviral antagonism of PML-nuclear bodies. After the infection of target cells, the herpesviral capsid is transported to the nuclear membrane and the viral DNA released into the nucleus through nuclear pores. The genome rapidly associates with PML nuclear bodies (PML-NBs). PML-NBs are considered as antiviral nuclear organelles that restrict gene expression from viral genomes, and PML-NB components PML, SP100, DAXX and ATRX as well as the transiently associated proteins IFI16 and HIRA have been shown to mediate this restriction. PML is an essential structural component of PML-NBs and depletion of PML disrupts PML-NBs. Herpesviruses in contrast have evolved mechanisms to counteract this restriction, in particular viral tegument and immediate-early proteins as depicted in the graph. ? Indicates hypothetical mode of interference.

All gammaherpesviruses like KSHV encode for at least one member of a viral protein family, the viral formylglycineamide ribonucleotide amidotransferase (vFGARAT) [89]. The vFGARATs are cellular FGARAT (also PFAS, EC 6.3.5.3) homologs, the enzyme that catalyzes the fourth step in the de novo purine biosynthesis pathway. Several family members have been shown to counteract the antiviral function of PML-NBs since the homology of the viral and the cellular gene were first described in 1997 [89,113]. In doing so, different gammaherpesviruses antagonize different components of PML-NBs. The vFGARAT of KSHV for example, ORF75, induces the degradation of ATRX and the relocalization of DAXX [114], whereas closely related human and monkey viruses apply different strategies $[89,93,115-117]$. vFGARATs are tegument proteins that enter the newly-infected cell together with the viral genome. Similar to ICP-0 of HSV-1 and pp71 of HCMV, it is thought that the immediate antagonism of PML-NBs upon entering of the nucleus is needed for efficient viral early gene expression. In addition, vFGARATs apparently have additional functions needed for viral infection and replication, including structural functions as tegument components and involvement in deamidation of target proteins [89,118-120]. This is also reflected by genetic depletion of ORF75 from the KSHV genome, which results in a replication-dead virus that cannot be explained solely by its effect on PML-NBs [114].

Intriguingly, the discussed pathways seem to be interconnected in several ways. It is established that upon initiation of a DDR, PML-NB numbers per cell increase and PML-NBs are recruited to sites of DNA damage. The PML-NB components DAXX and ATRX for example are important antagonists of the alternative lengthening of telomeres- (ALT-) pathway [121]. ALT is a recombination-based mechanism of telomere maintenance that gets activated during early development, and in a subset of cancer cells. One could speculate that the inactivation of ATRX and DAXX activates ALT (or other recombination-based pathways), and thereby contributes to recombination of the viral genome [122]. IFI16, the cellular sensor for dsDNA has, in turn, been shown to associate with PML-NBs, although the antiviral mechanisms by which PML-NB components like PML and ATRX restrict HSV-1 seem to be different, and not directly connected to IFI16 [20,123]. Along this line, a novel connection between IFI16, the DDR kinase ATM, and the cellular DNA-sensing pathway molecule STING has been demonstrated recently [124]. Upon DNA-damage, IFI16, ATM, and PARP1 form a complex that 
leads to non-canonical STING activation via TRAF6 activation, resulting in NF-kB activation [124]. In addition, the DDR proteins RNF8 and RNF168 have been shown to be negative regulators of PML [125]. An interesting viral protein that has been shown to alter both PML-NBs and the DDR is pUL35 of HCMV. pUL35 is part of the virion, interacts with pp71, and activates the HCMV MIEP together with pp71 [126]. The expression of pUL35 leads to formation of UL35 nuclear bodies within the nucleus [127]. Those bodies form independently of PML, but after the formation PML, Sp100, and DAXX, get recruited to UL35 bodies [127]. In addition, pUL35 has also been shown to activate the DDR by inducing 53BP1 and $\gamma \mathrm{H} 2 \mathrm{AX}$ foci [128].

Beside the cellular DNA sensors, DDR proteins and PML-NB components, there are a variety of other cellular proteins that have been demonstrated to inhibit herpesviral immediate-early gene expression, especially proteins involved in epigenetic regulation and chromatin remodeling. For example, in addition to its well-known role in the restriction of HIV, it was recently recognized that the human interferon induced dynamin-like GTPase MX2 (MxB) interferes with HSV-1 entry at a step after tegument dissociation but before viral genome uncoating and translocation into the nucleus [129-133]. Although the detailed mechanism of this restriction is not fully elucidated, it is clear that it requires the GTPase function of MX2.

Taken together, we think that herpesviruses have to counteract several cellular pathways to enable viral gene expression and prevent silencing of the viral genome immediately after infection. Specifically, cellular sensors of herpesviral DNA, DNA-damage proteins, and components of PML-nuclear bodies are described as antiviral restriction factors. In turn, members of all herpesvirus subfamilies have evolved efficient countermeasures to evade cellular intrinsic immunity, in particular by viral tegument proteins that enter the nucleus together with the viral genome. However further studies are needed to analyze this viral and cellular arms race in order to get more insights that might help to identify new targets for antiviral drugs that could be used for therapy of patients in the future.

Author Contributions: F.F and A.E. wrote the manuscript.

Funding: This work was supported by grants from the German Research Foundation CRC 796, TP B1 and EN423/5-1 (to A.E.), F.F. was further supported by a Marie Skłodowska-Curie Individual Fellowship from the European Union's Framework Program for Research and Innovation Horizon 2020 (2014-2020) under the Grant Agreement No. 703896, and the Interdisciplinary Center for Clinical Research Erlangen (IZKF, J57). A.E. also received funding by IZKF, A66.

Acknowledgments: We thank Elizabeth M. Holmes for critical reading of the manuscript.

Conflicts of Interest: The authors declare no conflict of interest.

\section{References}

1. Pellet, P.E.; Roizman, B. Fields Virology; Wolters Kluwer: Alfon am Rhein, The Netherlands, 2013.

2. Looker, K.J.; Magaret, A.S.; May, M.T.; Turner, K.M.; Vickerman, P.; Gottlieb, S.L.; Newman, L.M. Global and Regional Estimates of Prevalent and Incident Herpes Simplex Virus Type 1 Infections in 2012. PLoS ONE 2015, 10, e0140765. [CrossRef] [PubMed]

3. Emery, V.C.; Clark, D.A. HHV-6A, 6B, and 7: Persistence in the population, epidemiology and transmission. In Human Herpesviruses: Biology, Therapy, and Immunoprophylaxis; Cambridge University Press: Cambridge, UK, 2007.

4. Hjalgrim, H.; Friborg, J.; Melbye, M. The epidemiology of EBV and its association with malignant disease. In Human Herpesviruses: Biology, Therapy, and Immunoprophylaxis; Cambridge University Press: Cambridge, UK, 2007.

5. Liu, Y.T.; Jih, J.; Dai, X.; Bi, G.Q.; Zhou, Z.H. Cryo-EM structures of herpes simplex virus type 1 portal vertex and packaged genome. Nature 2019, 570, 257-261. [CrossRef] [PubMed]

6. Hornung, V.; Ablasser, A.; Charrel-Dennis, M.; Bauernfeind, F.; Horvath, G.; Caffrey, D.R.; Latz, E.; Fitzgerald, K.A. AIM2 recognizes cytosolic dsDNA and forms a caspase-1-activating inflammasome with ASC. Nature 2009, 458, 514-518. [CrossRef] [PubMed] 
7. Sun, L.; Wu, J.; Du, F.; Chen, X.; Chen, Z.J. Cyclic GMP-AMP synthase is a cytosolic DNA sensor that activates the type I interferon pathway. Science 2013, 339, 786-791. [CrossRef] [PubMed]

8. Wu, J.; Sun, L.; Chen, X.; Du, F.; Shi, H.; Chen, C.; Chen, Z.J. Cyclic GMP-AMP is an endogenous second messenger in innate immune signaling by cytosolic DNA. Science 2013, 339, 826-830. [CrossRef] [PubMed]

9. Knipe, D.M. Nuclear sensing of viral DNA, epigenetic regulation of herpes simplex virus infection, and innate immunity. Virology 2015, 479, 153-159. [CrossRef] [PubMed]

10. Kobiler, O.; Drayman, N.; Butin-Israeli, V.; Oppenheim, A. Virus strategies for passing the nuclear envelope barrier. Nucleus 2012, 3, 526-539. [CrossRef] [PubMed]

11. Orzalli, M.H.; Conwell, S.E.; Berrios, C.; DeCaprio, J.A.; Knipe, D.M. Nuclear interferon-inducible protein 16 promotes silencing of herpesviral and transfected DNA. Proc. Natl. Acad. Sci. USA 2013, 110, E4492-E4501. [CrossRef]

12. Orzalli, M.H.; DeLuca, N.A.; Knipe, D.M. Nuclear IFI16 induction of IRF-3 signaling during herpesviral infection and degradation of IFI16 by the viral ICP0 protein. Proc. Natl. Acad. Sci. USA 2012, 109, E3008-E3017. [CrossRef]

13. Li, T.; Diner, B.A.; Chen, J.; Cristea, I.M. Acetylation modulates cellular distribution and DNA sensing ability of interferon-inducible protein IFI16. Proc. Natl. Acad. Sci. USA 2012, 109, 10558-10563. [CrossRef]

14. Komatsu, T.; Nagata, K.; Wodrich, H. The Role of Nuclear Antiviral Factors against Invading DNA Viruses: The Immediate Fate of Incoming Viral Genomes. Viruses 2016, 8, 290. [CrossRef] [PubMed]

15. Unterholzner, L.; Keating, S.E.; Baran, M.; Horan, K.A.; Jensen, S.B.; Sharma, S.; Sirois, C.M.; Jin, T.; Latz, E.; Xiao, T.S.; et al. IFI16 is an innate immune sensor for intracellular DNA. Nat. Immunol. 2010, 11, 997-1004. [CrossRef] [PubMed]

16. Ansari, M.A.; Dutta, S.; Veettil, M.V.; Dutta, D.; Iqbal, J.; Kumar, B.; Roy, A.; Chikoti, L.; Singh, V.V.; Chandran, B. Herpesvirus Genome Recognition Induced Acetylation of Nuclear IFI16 Is Essential for Its Cytoplasmic Translocation, Inflammasome and IFN-beta Responses. PLoS Pathog. 2015, 11, e1005019. [CrossRef]

17. Orzalli, M.H.; Broekema, N.M.; Diner, B.A.; Hancks, D.C.; Elde, N.C.; Cristea, I.M.; Knipe, D.M. cGAS-mediated stabilization of IFI16 promotes innate signaling during herpes simplex virus infection. Proc. Natl. Acad. Sci. USA 2015, 112, E1773-E1781. [CrossRef] [PubMed]

18. Everett, R.D. Dynamic Response of IFI16 and Promyelocytic Leukemia Nuclear Body Components to Herpes Simplex Virus 1 Infection. J. Virol. 2016, 90, 167-179. [CrossRef] [PubMed]

19. Lum, K.K.; Howard, T.R.; Pan, C.; Cristea, I.M. Charge-Mediated Pyrin Oligomerization Nucleates Antiviral IFI16 Sensing of Herpesvirus DNA. MBio 2019. [CrossRef] [PubMed]

20. Merkl, P.E.; Knipe, D.M. Role for a Filamentous Nuclear Assembly of IFI16, DNA, and Host Factors in Restriction of Herpesviral Infection. MBio 2019. [CrossRef]

21. Gariano, G.R.; Dell'Oste, V.; Bronzini, M.; Gatti, D.; Luganini, A.; De Andrea, M.; Gribaudo, G.; Gariglio, M.; Landolfo, $\mathrm{S}$. The intracellular DNA sensor IFI16 gene acts as restriction factor for human cytomegalovirus replication. PLoS Pathog. 2012, 8, e1002498. [CrossRef]

22. Li, T.; Chen, J.; Cristea, I.M. Human cytomegalovirus tegument protein pUL83 inhibits IFI16-mediated DNA sensing for immune evasion. Cell Host Microbe. 2013, 14, 591-599. [CrossRef]

23. Cuchet-Lourenco, D.; Anderson, G.; Sloan, E.; Orr, A.; Everett, R.D. The viral ubiquitin ligase ICP0 is neither sufficient nor necessary for degradation of the cellular DNA sensor IFI16 during herpes simplex virus 1 infection. J. Virol. 2013, 87, 13422-13432. [CrossRef]

24. Diner, B.A.; Lum, K.K.; Javitt, A.; Cristea, I.M. Interactions of the Antiviral Factor Interferon Gamma-Inducible Protein 16 (IFI16) Mediate Immune Signaling and Herpes Simplex Virus-1 Immunosuppression. Mol. Cell Proteomics. 2015, 14, 2341-2356. [CrossRef] [PubMed]

25. Orzalli, M.H.; Broekema, N.M.; Knipe, D.M. Relative Contributions of Herpes Simplex Virus 1 ICP0 and vhs to Loss of Cellular IFI16 Vary in Different Human Cell Types. J. Virol. 2016, 90, 8351-8359. [CrossRef] [PubMed]

26. Roy, A.; Dutta, D.; Iqbal, J.; Pisano, G.; Gjyshi, O.; Ansari, M.A.; Kumar, B.; Chandran, B. Nuclear Innate Immune DNA Sensor IFI16 Is Degraded during Lytic Reactivation of Kaposi's Sarcoma-Associated Herpesvirus (KSHV): Role of IFI16 in Maintenance of KSHV Latency. J. Virol. 2016, 90, 8822-8841. [CrossRef] [PubMed] 
27. Kerur, N.; Veettil, M.V.; Sharma-Walia, N.; Bottero, V.; Sadagopan, S.; Otageri, P.; Chandran, B. IFI16 acts as a nuclear pathogen sensor to induce the inflammasome in response to Kaposi Sarcoma-associated herpesvirus infection. Cell Host Microbe. 2011, 9, 363-375. [CrossRef] [PubMed]

28. Dutta, D.; Dutta, S.; Veettil, M.V.; Roy, A.; Ansari, M.A.; Iqbal, J.; Chikoti, L.; Kumar, B.; Johnson, K.E.; Chandran, B. BRCA1 Regulates IFI16 Mediated Nuclear Innate Sensing of Herpes Viral DNA and Subsequent Induction of the Innate Inflammasome and Interferon-beta Responses. PLoS Pathog. 2015, 11, e1005030. [CrossRef]

29. Iqbal, J.; Ansari, M.A.; Kumar, B.; Dutta, D.; Roy, A.; Chikoti, L.; Pisano, G.; Dutta, S.; Vahedi, S.; Veettil, M.V.; et al. Histone H2B-IFI16 Recognition of Nuclear Herpesviral Genome Induces Cytoplasmic Interferon-beta Responses. PLoS Pathog. 2016, 12, e1005967. [CrossRef]

30. Johnson, K.E.; Bottero, V.; Flaherty, S.; Dutta, S.; Singh, V.V.; Chandran, B. IFI16 restricts HSV-1 replication by accumulating on the hsv-1 genome, repressing HSV-1 gene expression, and directly or indirectly modulating histone modifications. PLoS Pathog. 2014, 10, e1004503. [CrossRef]

31. Alandijany, T.; Roberts, A.P.E.; Conn, K.L.; Loney, C.; McFarlane, S.; Orr, A.; Boutell, C. Distinct temporal roles for the promyelocytic leukaemia (PML) protein in the sequential regulation of intracellular host immunity to HSV-1 infection. PLoS Pathog. 2018, 14, e1006769. [CrossRef]

32. Komatsu, T.; Nagata, K.; Wodrich, H. An Adenovirus DNA Replication Factor, but Not Incoming Genome Complexes, Targets PML Nuclear Bodies. J. Virol. 2016, 90, 1657-1667. [CrossRef]

33. Komatsu, T.; Will, H.; Nagata, K.; Wodrich, H. Imaging analysis of nuclear antiviral factors through direct detection of incoming adenovirus genome complexes. Biochem. Biophys. Res. Commun. 2016, 473, 200-205. [CrossRef]

34. Cabral, J.M.; Oh, H.S.; Knipe, D.M. ATRX promotes maintenance of herpes simplex virus heterochromatin during chromatin stress. Elife 2018. [CrossRef] [PubMed]

35. Orzalli, M.H.; Knipe, D.M. Cellular sensing of viral DNA and viral evasion mechanisms. Annu. Rev. Microbiol. 2014, 68, 477-492. [CrossRef] [PubMed]

36. Stempel, M.; Chan, B.; Brinkmann, M.M. Coevolution pays off: Herpesviruses have the license to escape the DNA sensing pathway. Med. Microbiol. Immunol. 2019. [CrossRef] [PubMed]

37. Weitzman, M.D.; Fradet-Turcotte, A. Virus DNA Replication and the Host DNA Damage Response. Annu. Rev. Virol. 2018, 5, 141-164. [CrossRef] [PubMed]

38. Shah, G.A.; O'Shea, C.C. Viral and Cellular Genomes Activate Distinct DNA Damage Responses. Cell 2015, 162, 987-1002. [CrossRef]

39. Stracker, T.H.; Carson, C.T.; Weitzman, M.D. Adenovirus oncoproteins inactivate the Mre11-Rad50-NBS1 DNA repair complex. Nature 2002, 418, 348-352. [CrossRef] [PubMed]

40. Baker, A.; Rohleder, K.J.; Hanakahi, L.A.; Ketner, G. Adenovirus E4 34k and E1b 55k oncoproteins target host DNA ligase IV for proteasomal degradation. J. Virol. 2007, 81, 7034-7040. [CrossRef]

41. Schrank, B.; Gautier, J. Assembling nuclear domains: Lessons from DNA repair. J. Cell Biol. 2019. [CrossRef]

42. Smith, S.; Reuven, N.; Mohni, K.N.; Schumacher, A.J.; Weller, S.K. Structure of the herpes simplex virus 1 genome: Manipulation of nicks and gaps can abrogate infectivity and alter the cellular DNA damage response. J. Virol. 2014, 88, 10146-10156. [CrossRef]

43. Blackburn, E.H.; Epel, E.S.; Lin, J. Human telomere biology: A contributory and interactive factor in aging, disease risks, and protection. Science 2015, 350, 1193-1198. [CrossRef]

44. Flamand, L. Chromosomal Integration by Human Herpesviruses 6A and 6B. Adv. Exp. Med. Biol. 2018, 1045, 209-226. [PubMed]

45. Nacheva, E.P.; Ward, K.N.; Brazma, D.; Virgili, A.; Howard, J.; Leong, H.N.; Clark, D.A. Human herpesvirus 6 integrates within telomeric regions as evidenced by five different chromosomal sites. J. Med. Virol. 2008, 80, 1952-1958. [CrossRef] [PubMed]

46. Arbuckle, J.H.; Medveczky, M.M.; Luka, J.; Hadley, S.H.; Luegmayr, A.; Ablashi, D.; Lund, T.C.; Tolar, J.; De Meirleir, K.; Montoya, J.G.; et al. The latent human herpesvirus-6A genome specifically integrates in telomeres of human chromosomes in vivo and in vitro. Proc. Natl. Acad. Sci. USA 2010, 107, 5563-5568. [CrossRef] [PubMed]

47. Mohni, K.N.; Dee, A.R.; Smith, S.; Schumacher, A.J.; Weller, S.K. Efficient herpes simplex virus 1 replication requires cellular ATR pathway proteins. J. Virol. 2013, 87, 531-542. [CrossRef] [PubMed] 
48. Mohni, K.N.; Livingston, C.M.; Cortez, D.; Weller, S.K. ATR and ATRIP are recruited to herpes simplex virus type 1 replication compartments even though ATR signaling is disabled. J. Virol. 2010, 84, 12152-12164. [CrossRef] [PubMed]

49. Edwards, T.G.; Bloom, D.C.; Fisher, C. The ATM and Rad3-Related (ATR) Protein Kinase Pathway Is Activated by Herpes Simplex Virus 1 and Required for Efficient Viral Replication. J. Virol. 2018. [CrossRef] [PubMed]

50. Albright, B.S.; Kosinski, A.; Szczepaniak, R.; Cook, E.A.; Stow, N.D.; Conway, J.F.; Weller, S.K. The putative herpes simplex virus 1 chaperone protein UL32 modulates disulfide bond formation during infection. J. Virol. 2015, 89, 443-453. [CrossRef] [PubMed]

51. Mohni, K.N.; Smith, S.; Dee, A.R.; Schumacher, A.J.; Weller, S.K. Herpes simplex virus type 1 single strand DNA binding protein and helicase/primase complex disable cellular ATR signaling. PLoS Pathog. 2013, 9, e1003652. [CrossRef] [PubMed]

52. Wilkinson, D.E.; Weller, S.K. Herpes simplex virus type I disrupts the ATR-dependent DNA-damage response during lytic infection. J. Cell Sci. 2006, 119, 2695-2703. [CrossRef] [PubMed]

53. Lilley, C.E.; Carson, C.T.; Muotri, A.R.; Gage, F.H.; Weitzman, M.D. DNA repair proteins affect the lifecycle of herpes simplex virus 1. Proc. Natl. Acad. Sci. USA 2005, 102, 5844-5849. [CrossRef] [PubMed]

54. Lilley, C.E.; Schwartz, R.A.; Weitzman, M.D. Using or abusing: Viruses and the cellular DNA damage response. Trends. Microbiol. 2007, 15, 119-126. [CrossRef] [PubMed]

55. Dembowski, J.A.; Dremel, S.E.; DeLuca, N.A. Replication-Coupled Recruitment of Viral and Cellular Factors to Herpes Simplex Virus Type 1 Replication Forks for the Maintenance and Expression of Viral Genomes. PLoS Pathog. 2017, 13, e1006166. [CrossRef] [PubMed]

56. Hollingworth, R.; Horniblow, R.D.; Forrest, C.; Stewart, G.S.; Grand, R.J. Localization of Double-Strand Break Repair Proteins to Viral Replication Compartments following Lytic Reactivation of Kaposi's Sarcoma-Associated Herpesvirus. J. Virol. 2017. [CrossRef] [PubMed]

57. Hollingworth, R.; Skalka, G.L.; Stewart, G.S.; Hislop, A.D.; Blackbourn, D.J.; Grand, R.J. Activation of DNA Damage Response Pathways during Lytic Replication of KSHV. Viruses 2015, 7, 2908-2927. [CrossRef] [PubMed]

58. O’Dowd, J.M.; Zavala, A.G.; Brown, C.J.; Mori, T.; Fortunato, E.A. HCMV-infected cells maintain efficient nucleotide excision repair of the viral genome while abrogating repair of the host genome. PLoS Pathog. 2012, 8, e1003038. [CrossRef] [PubMed]

59. Luo, M.H.; Rosenke, K.; Czornak, K.; Fortunato, E.A. Human cytomegalovirus disrupts both ataxia telangiectasia mutated protein (ATM)- and ATM-Rad3-related kinase-mediated DNA damage responses during lytic infection. J. Virol. 2007, 81, 1934-1950. [CrossRef] [PubMed]

60. Castillo, J.P.; Frame, F.M.; Rogoff,H.A.; Pickering, M.T.; Yurochko, A.D.; Kowalik, T.F. Human cytomegalovirus IE1-72 activates ataxia telangiectasia mutated kinase and a p53/p21-mediated growth arrest response. J. Virol. 2005, 79, 11467-11475. [CrossRef] [PubMed]

61. Xiaofei, E.; Pickering, M.T.; Debatis, M.; Castillo, J.; Lagadinos, A.; Wang, S.; Lu, S.; Kowalik, T.F. An E2F1-mediated DNA damage response contributes to the replication of human cytomegalovirus. PLoS Pathog. 2011, 7, e1001342. [CrossRef]

62. Xiaofei, E.; Savidis, G.; Chin, C.R.; Wang, S.; Lu, S.; Brass, A.L.; Kowalik, T.F. A novel DDB2-ATM feedback loop regulates human cytomegalovirus replication. J. Virol. 2014, 88, 2279-2290.

63. Xiaofei, E.; Kowalik, T.F. The DNA damage response induced by infection with human cytomegalovirus and other viruses. Viruses 2014, 6, 2155-2185.

64. Spector, D.H. Human cytomegalovirus riding the cell cycle. Med. Microbiol. Immunol. 2015, 204, 409-419. [CrossRef] [PubMed]

65. Trigg, B.J.; Lauer, K.B.; Fernandes Dos Santos, P.; Coleman, H.; Balmus, G.; Mansur, D.S.; Ferguson, B.J. The Non-Homologous End Joining Protein PAXX Acts to Restrict HSV-1 Infection. Viruses 2017, 9, 342. [CrossRef] [PubMed]

66. Reichel, A.; Stilp, A.C.; Scherer, M.; Reuter, N.; Lukassen, S.; Kasmapour, B.; Schreiner, S.; Cicin-Sain, L.; Winterpacht, A.; Stamminger, T. Chromatin-Remodeling Factor SPOC1 Acts as a Cellular Restriction Factor against Human Cytomegalovirus by Repressing the Major Immediate Early Promoter. J. Virol. 2018. [CrossRef] [PubMed] 
67. Schreiner, S.; Kinkley, S.; Burck, C.; Mund, A.; Wimmer, P.; Schubert, T.; Groitl, P.; Will, H.; Dobner, T. SPOC1-mediated antiviral host cell response is antagonized early in human adenovirus type 5 infection. PLoS Pathog. 2013, 9, e1003775. [CrossRef] [PubMed]

68. Mund, A.; Schubert, T.; Staege, H.; Kinkley, S.; Reumann, K.; Kriegs, M.; Fritsch, L.; Battisti, V.; Ait-Si-Ali, S.; Hoffbeck, A.S.; et al. SPOC1 modulates DNA repair by regulating key determinants of chromatin compaction and DNA damage response. Nucleic. Acids. Res. 2012, 40, 11363-11379. [CrossRef] [PubMed]

69. Jackson, S.A.; DeLuca, N.A. Relationship of herpes simplex virus genome configuration to productive and persistent infections. Proc. Natl. Acad. Sci. USA 2003, 100, 7871-7876. [CrossRef]

70. Strang, B.L.; Stow, N.D. Circularization of the herpes simplex virus type 1 genome upon lytic infection. J. Virol. 2005, 79, 12487-12494. [CrossRef]

71. Skaliter, R.; Lehman, I.R. Rolling circle DNA replication in vitro by a complex of herpes simplex virus type 1-encoded enzymes. Proc. Natl. Acad. Sci. USA 1994, 91, 10665-10669. [CrossRef]

72. Skaliter, R.; Makhov, A.M.; Griffith, J.D.; Lehman, I.R. Rolling circle DNA replication by extracts of herpes simplex virus type 1-infected human cells. J. Virol. 1996, 70, 1132-1136.

73. Zhang, X.; Efstathiou, S.; Simmons, A. Identification of novel herpes simplex virus replicative intermediates by field inversion gel electrophoresis: Implications for viral DNA amplification strategies. Virology 1994, 202, 530-539. [CrossRef]

74. Severini, A.; Morgan, A.R.; Tovell, D.R.; Tyrrell, D.L. Study of the structure of replicative intermediates of HSV-1 DNA by pulsed-field gel electrophoresis. Virology 1994, 200, 428-435. [CrossRef]

75. Severini, A.; Scraba, D.G.; Tyrrell, D.L. Branched structures in the intracellular DNA of herpes simplex virus type 1. J. Virol. 1996, 70, 3169-3175. [PubMed]

76. Wilkinson, D.E.; Weller, S.K. The role of DNA recombination in herpes simplex virus DNA replication. IUBMB Life 2003, 55, 451-458. [CrossRef] [PubMed]

77. Dembowski, J.A.; DeLuca, N.A. Temporal Viral Genome-Protein Interactions Define Distinct Stages of Productive Herpesviral Infection. MBio 2018. [CrossRef] [PubMed]

78. Ligasova, A.; Liboska, R.; Friedecky, D.; Micova, K.; Adam, T.; Ozdian, T.; Rosenberg, I.; Koberna, K. Dr Jekyll and Mr Hyde: A strange case of 5-ethynyl-2'-deoxyuridine and 5-ethynyl-2'-deoxycytidine. Open Biol. 2016. [CrossRef] [PubMed]

79. Kohlmeier, F.; Maya-Mendoza, A.; Jackson, D.A. EdU induces DNA damage response and cell death in mESC in culture. Chromosome. Res. 2013, 21, 87-100. [CrossRef] [PubMed]

80. Parkinson, J.; Lees-Miller, S.P.; Everett, R.D. Herpes simplex virus type 1 immediate-early protein vmw 110 induces the proteasome-dependent degradation of the catalytic subunit of DNA-dependent protein kinase. J. Virol. 1999, 73, 650-657. [PubMed]

81. Lees-Miller, S.P.; Long, M.C.; Kilvert, M.A.; Lam, V.; Rice, S.A.; Spencer, C.A. Attenuation of DNA-dependent protein kinase activity and its catalytic subunit by the herpes simplex virus type 1 transactivator ICP0. J. Virol. 1996, 70, 7471-7477. [PubMed]

82. Taylor, T.J.; Knipe, D.M. Proteomics of herpes simplex virus replication compartments: Association of cellular DNA replication, repair, recombination, and chromatin remodeling proteins with ICP8. J. Virol. 2004, 78, 5856-5866. [CrossRef] [PubMed]

83. Lilley, C.E.; Chaurushiya, M.S.; Boutell, C.; Everett, R.D.; Weitzman, M.D. The intrinsic antiviral defense to incoming HSV-1 genomes includes specific DNA repair proteins and is counteracted by the viral protein ICP0. PLoS Pathog. 2011, 7, e1002084. [CrossRef]

84. Lilley, C.E.; Chaurushiya, M.S.; Boutell, C.; Landry, S.; Suh, J.; Panier, S.; Everett, R.D.; Stewart, G.S.; Durocher, D.; Weitzman, M.D. A viral E3 ligase targets RNF8 and RNF168 to control histone ubiquitination and DNA damage responses. EMBO J. 2010, 29, 943-955. [CrossRef] [PubMed]

85. Mattiroli, F.; Vissers, J.H.; van Dijk, W.J.; Ikpa, P.; Citterio, E.; Vermeulen, W.; Marteijn, J.A.; Sixma, T.K. RNF168 ubiquitinates K13-15 on H2A/H2AX to drive DNA damage signaling. Cell 2012, 150, 1182-1195. [CrossRef] [PubMed]

86. Lallemand-Breitenbach, V.; de Thé, H. PML nuclear bodies. Cold Spring Harb. Perspect. Biol. 2010. [CrossRef] [PubMed]

87. Lallemand-Breitenbach, V.; de Thé, H. PML nuclear bodies: From architecture to function. Curr. Opin. Cell Biol. 2018, 52, 154-161. [CrossRef] [PubMed] 
88. Tavalai, N.; Stamminger, T. New insights into the role of the subnuclear structure ND10 for viral infection. Biochim. Biophys. Acta. 2008, 1783, 2207-2221. [CrossRef] [PubMed]

89. Full, F.; Hahn, A.S.; Grosskopf, A.K.; Ensser, A. Gammaherpesviral Tegument Proteins, PML-Nuclear Bodies and the Ubiquitin-Proteasome System. Viruses 2017, 9, 308. [CrossRef] [PubMed]

90. Scherer, M.; Schilling, E.M.; Stamminger, T. The Human CMV IE1 Protein: An Offender of PML Nuclear Bodies. Adv. Anat. Embryol. Cell Biol. 2017, 223, 77-94. [PubMed]

91. Schreiner, S.; Burck, C.; Glass, M.; Groitl, P.; Wimmer, P.; Kinkley, S.; Mund, A.; Everett, R.D.; Dobner, T. Control of human adenovirus type 5 gene expression by cellular Daxx/ATRX chromatin-associated complexes. Nucleic. Acids. Res. 2013, 41, 3532-3550. [CrossRef]

92. Albright, E.R.; Kalejta, R.F. Canonical and Variant Forms of Histone H3 Are Deposited onto the Human Cytomegalovirus Genome during Lytic and Latent Infections. J. Virol. 2016, 90, 10309-10320. [CrossRef]

93. Tsai, K.; Chan, L.; Gibeault, R.; Conn, K.; Dheekollu, J.; Domsic, J.; Marmorstein, R.; Schang, L.M.; Lieberman, P.M. Viral reprogramming of the Daxx histone H3.3 chaperone during early Epstein-Barr virus infection. J. Virol. 2014, 88, 14350-14363. [CrossRef] [PubMed]

94. McFarlane, S.; Orr, A.; Roberts, A.P.E.; Conn, K.L.; Iliev, V.; Loney, C.; da Silva Filipe, A.; Smollett, K.; Gu, Q.; Robertson, N.; et al. The histone chaperone HIRA promotes the induction of host innate immune defences in response to HSV-1 infection. PLoS Pathog. 2019, 15, e1007667. [CrossRef] [PubMed]

95. Rai, T.S.; Glass, M.; Cole, J.J.; Rather, M.I.; Marsden, M.; Neilson, M.; Brock, C.; Humphreys, I.R.; Everett, R.D.; Adams, P.D. Histone chaperone HIRA deposits histone H3.3 onto foreign viral DNA and contributes to anti-viral intrinsic immunity. Nucleic. Acids. Res. 2017, 45, 11673-11683. [CrossRef] [PubMed]

96. Lee, J.S.; Raja, P.; Knipe, D.M. Herpesviral ICP0 Protein Promotes Two Waves of Heterochromatin Removal on an Early Viral Promoter during Lytic Infection. MBio 2016, 7, e02007-e02015. [CrossRef] [PubMed]

97. Ishov, A.M.; Stenberg, R.M.; Maul, G.G. Human cytomegalovirus immediate early interaction with host nuclear structures: Definition of an immediate transcript environment. J. Cell Biol. 1997, 138, 5-16. [CrossRef] [PubMed]

98. Nitzsche, A.; Paulus, C.; Nevels, M. Temporal dynamics of cytomegalovirus chromatin assembly in productively infected human cells. J. Virol. 2008, 82, 11167-11180. [CrossRef] [PubMed]

99. Woodhall, D.L.; Groves, I.J.; Reeves, M.B.; Wilkinson, G.; Sinclair, J.H. Human Daxx-mediated repression of human cytomegalovirus gene expression correlates with a repressive chromatin structure around the major immediate early promoter. J. Biol. Chem. 2006, 281, 37652-37660. [CrossRef] [PubMed]

100. Maul, G.G.; Ishov, A.M.; Everett, R.D. Nuclear domain 10 as preexisting potential replication start sites of herpes simplex virus type-1. Virology 1996, 217, 67-75. [CrossRef]

101. Scherer, M.; Stamminger, T. Emerging Role of PML Nuclear Bodies in Innate Immune Signaling. J. Virol. 2016, 90, 5850-5854. [CrossRef]

102. Cliffe, A.R.; Knipe, D.M. Herpes simplex virus ICP0 promotes both histone removal and acetylation on viral DNA during lytic infection. J. Virol. 2008, 82, 12030-12038. [CrossRef]

103. Herrera, F.J.; Triezenberg, S.J. VP16-dependent association of chromatin-modifying coactivators and underrepresentation of histones at immediate-early gene promoters during herpes simplex virus infection. J. Virol. 2004, 78, 9689-9696. [CrossRef]

104. Maul, G.G.; Everett, R.D. The nuclear location of PML, a cellular member of the C3HC4 zinc-binding domain protein family, is rearranged during herpes simplex virus infection by the C3HC4 viral protein ICP0. J. Gen. Virol. 1994, 75, 1223-1233. [CrossRef] [PubMed]

105. Everett, R.D.; Freemont, P.; Saitoh, H.; Dasso, M.; Orr, A.; Kathoria, M.; Parkinson, J. The disruption of ND10 during herpes simplex virus infection correlates with the Vmw110- and proteasome-dependent loss of several PML isoforms. J. Virol. 1998, 72, 6581-6591. [PubMed]

106. Glass, M.; Everett, R.D. Components of promyelocytic leukemia nuclear bodies (ND10) act cooperatively to repress herpesvirus infection. J. Virol. 2013, 87, 2174-2185. [CrossRef] [PubMed]

107. Everett, R.D.; Rechter, S.; Papior, P.; Tavalai, N.; Stamminger, T.; Orr, A. PML contributes to a cellular mechanism of repression of herpes simplex virus type 1 infection that is inactivated by ICP0. J. Virol. 2006, 80, 7995-8005. [CrossRef] [PubMed]

108. Boutell, C.; Cuchet-Lourenco, D.; Vanni, E.; Orr, A.; Glass, M.; McFarlane, S.; Everett, R.D. A viral ubiquitin ligase has substrate preferential SUMO targeted ubiquitin ligase activity that counteracts intrinsic antiviral defence. PLoS Pathog. 2011, 7, e1002245. [CrossRef] [PubMed] 
109. Hofmann, H.; Sindre, H.; Stamminger, T. Functional interaction between the pp71 protein of human cytomegalovirus and the PML-interacting protein human Daxx. J. Virol. 2002, 76, 5769-5783. [CrossRef] [PubMed]

110. Ishov, A.M.; Vladimirova, O.V.; Maul, G.G. Daxx-mediated accumulation of human cytomegalovirus tegument protein pp71 at ND10 facilitates initiation of viral infection at these nuclear domains. J. Virol. 2002, 76, 7705-7712. [CrossRef] [PubMed]

111. Korioth, F.; Maul, G.G.; Plachter, B.; Stamminger, T.; Frey, J. The nuclear domain 10 (ND10) is disrupted by the human cytomegalovirus gene product IE1. Exp. Cell Res. 1996, 229, 155-158. [CrossRef]

112. Schilling, E.M.; Scherer, M.; Reuter, N.; Schweininger, J.; Muller, Y.A.; Stamminger, T. The Human Cytomegalovirus IE1 Protein Antagonizes PML Nuclear Body-Mediated Intrinsic Immunity via the Inhibition of PML De Novo SUMOylation. J. Virol. 2017, 91, e02049-16. [CrossRef]

113. Ensser, A.; Pflanz, R.; Fleckenstein, B. Primary structure of the alcelaphine herpesvirus 1 genome. J. Virol. 1997, 71, 6517-6525.

114. Full, F.; Jungnickl, D.; Reuter, N.; Bogner, E.; Brulois, K.; Scholz, B.; Sturzl, M.; Myoung, J.; Jung, J.U.; Stamminger, T.; et al. Kaposi's sarcoma associated herpesvirus tegument protein ORF75 is essential for viral lytic replication and plays a critical role in the antagonization of ND10-instituted intrinsic immunity. PLoS Pathog. 2014, 10, e1003863. [CrossRef] [PubMed]

115. Full, F.; Reuter, N.; Zielke, K.; Stamminger, T.; Ensser, A. Herpesvirus saimiri antagonizes nuclear domain 10-instituted intrinsic immunity via an ORF3-mediated selective degradation of cellular protein Sp100. J. Virol. 2012, 86, 3541-3553. [CrossRef] [PubMed]

116. Hahn, A.S.; Grosskopf, A.K.; Jungnickl, D.; Scholz, B.; Ensser, A. Viral FGARAT Homolog ORF75 of Rhesus Monkey Rhadinovirus Effects Proteasomal Degradation of the ND10 Components SP100 and PML. J. Virol. 2016, 90, 8013-8028. [CrossRef] [PubMed]

117. Tsai, K.; Thikmyanova, N.; Wojcechowskyj, J.A.; Delecluse, H.J.; Lieberman, P.M. EBV tegument protein BNRF1 disrupts DAXX-ATRX to activate viral early gene transcription. PLoS Pathog. 2011, 7, e1002376. [CrossRef] [PubMed]

118. He, S.; Zhao, J.; Song, S.; He, X.; Minassian, A.; Zhou, Y.; Zhang, J.; Brulois, K.; Wang, Y.; Cabo, J.; et al. Viral pseudo-enzymes activate RIG-I via deamidation to evade cytokine production. Mol. Cell 2015, 58, 134-146. [CrossRef] [PubMed]

119. Zhao, J.; Li, J.; Xu, S.; Feng, P. Emerging Roles of Protein Deamidation in Innate Immune Signaling. J. Virol. 2016, 90, 4262-4268. [CrossRef]

120. Zhao, J.; Zeng, Y.; Xu, S.; Chen, J.; Shen, G.; Yu, C.; Knipe, D.; Yuan, W.; Peng, J.; Xu, W.; et al. A Viral Deamidase Targets the Helicase Domain of RIG-I to Block RNA-Induced Activation. Cell Host Microbe. 2016, 20, 770-784. [CrossRef]

121. Clynes, D.; Jelinska, C.; Xella, B.; Ayyub, H.; Scott, C.; Mitson, M.; Taylor, S.; Higgs, D.R.; Gibbons, R.J. Suppression of the alternative lengthening of telomere pathway by the chromatin remodelling factor ATRX. Nat. Commun. 2015. [CrossRef]

122. Wang, Z.; Deng, Z.; Tutton, S.; Lieberman, P.M. The Telomeric Response to Viral Infection. Viruses 2017, 9, 218. [CrossRef]

123. Merkl, P.E.; Orzalli, M.H.; Knipe, D.M. Mechanisms of Host IFI16, PML, and Daxx Protein Restriction of Herpes Simplex Virus 1 Replication. J. Virol. 2018. [CrossRef]

124. Dunphy, G.; Flannery, S.M.; Almine, J.F.; Connolly, D.J.; Paulus, C.; Jonsson, K.L.; Jakobsen, M.R.; Nevels, M.M.; Bowie, A.G.; Unterholzner, L. Non-canonical Activation of the DNA Sensing Adaptor STING by ATM and IFI16 Mediates NF-kappaB Signaling after Nuclear DNA Damage. Mol. Cell 2018, 71, 745-760. [CrossRef] [PubMed]

125. Shire, K.; Wong, A.I.; Tatham, M.H.; Anderson, O.F.; Ripsman, D.; Gulstene, S.; Moffat, J.; Hay, R.T.; Frappier, L. Identification of RNF168 as a PML nuclear body regulator. J. Cell Sci. 2016, 129, 580-591. [CrossRef] [PubMed]

126. Schierling, K.; Stamminger, T.; Mertens, T.; Winkler, M. Human cytomegalovirus tegument proteins ppUL82 (pp71) and ppUL35 interact and cooperatively activate the major immediate-early enhancer. J. Virol. 2004, 78, 9512-9523. [CrossRef] [PubMed]

127. Salsman, J.; Wang, X.; Frappier, L. Nuclear body formation and PML body remodeling by the human cytomegalovirus protein UL35. Virology 2011, 414, 119-129. [CrossRef] [PubMed] 
128. Salsman, J.; Jagannathan, M.; Paladino, P.; Chan, P.K.; Dellaire, G.; Raught, B.; Frappier, L. Proteomic profiling of the human cytomegalovirus UL35 gene products reveals a role for UL35 in the DNA repair response. J. Virol. 2012, 86, 806-820. [CrossRef] [PubMed]

129. Schilling, M.; Bulli, L.; Weigang, S.; Graf, L.; Naumann, S.; Patzina, C.; Wagner, V.; Bauersfeld, L.; Goujon, C.; Hengel, H.; et al. Human MxB Protein Is a Pan-herpesvirus Restriction Factor. J. Virol. 2018. [CrossRef] [PubMed]

130. Kane, M.; Yadav, S.S.; Bitzegeio, J.; Kutluay, S.B.; Zang, T.; Wilson, S.J.; Schoggins, J.W.; Rice, C.M.; Yamashita, M.; Hatziioannou, T.; et al. MX2 is an interferon-induced inhibitor of HIV-1 infection. Nature 2013, 502, 563-566. [CrossRef] [PubMed]

131. Goujon, C.; Moncorge, O.; Bauby, H.; Doyle, T.; Ward, C.C.; Schaller, T.; Hue, S.; Barclay, W.S.; Schulz, R.; Malim, M.H. Human MX2 is an interferon-induced post-entry inhibitor of HIV-1 infection. Nature 2013, 502, 559-562. [CrossRef]

132. Crameri, M.; Bauer, M.; Caduff, N.; Walker, R.; Steiner, F.; Franzoso, F.D.; Gujer, C.; Boucke, K.; Kucera, T.; Zbinden, A.; et al. MxB is an interferon-induced restriction factor of human herpesviruses. Nat. Commun. 2018. [CrossRef]

133. Jaguva Vasudevan, A.A.; Bahr, A.; Grothmann, R.; Singer, A.; Haussinger, D.; Zimmermann, A.; Munk, C. MXB inhibits murine cytomegalovirus. Virology 2018, 522, 158-167. [CrossRef]

(C) 2019 by the authors. Licensee MDPI, Basel, Switzerland. This article is an open access article distributed under the terms and conditions of the Creative Commons Attribution (CC BY) license (http://creativecommons.org/licenses/by/4.0/). 